\title{
PROGRAM KEMITRAAN MASYARAKAT USAHA KERIPIK PISANG MENGANDUNG ANTIOKSIDAN DI KECAMATAN BUKIT RAYA
}

\author{
Rini Lestari ${ }^{1}$, Tri Rahayuningsih ${ }^{2}$ \\ 1) Program Studi D III Analis Farmasi dan Makanan, Fakultas Kedokteran dan Ilmu \\ Kesehatan, Universitas Abdurrab, Pekanbaru \\ 2) Program Studi S1 Psikologi, Fakultas Psikologi, Universitas Abdurrab, Pekanbaru \\ Email: rini.lestari@univrab.ac.id
}

\begin{abstract}
ABSTRAK
Keripik pisang umumnya masih diproduksi oleh industri rumah tangga dalam skala kecil. Industri rumah tangga terkendala untuk meningkatkan produksi karena minimnya aplikasi Iptek dalam proses pengolahan dan kurangnya teknik pemasaran. Berdasarkan latar belakang ini kami melaksanakan kegiatan pengabdian Program Kemitraan Masyarakat (PKM) dengan mitra pengabdian produsen keripik pisang yang berada di kecamatan Bukit Raya, Kota Pekanbaru, Propinsi Riau. Kegiatan pengabdian yang dilaksanakan yaitu pelatihan pembuatan keripik pisang mengandung antioksidan, pemberian bantuan peralatan dan bahan untuk meningkatkan produksi, pelatihan manajemen SDM kewirausahaan, bimbingan teknis strategi marketing dan kerjasama, pendampingan pembuatan desain label kemasan, pendampingan pengurusan izin P-IRT dan sertifikat halal. Hasil kegiatan ini antara lain adanya peningkatan keterampilan mitra dalam memproduksi keripik pisang, peningkatan skala produksi, produk keripik pisang memiliki izin P-IRT dan sertifikat halal, peningkatan penghasilan mitra menjadi dua kali lipat dari sebelumnya. Dari kegiatan ini dapat disimpulkan bahwa permasalahan yang dihadapi oleh mitra sebelum kegiatan pengabdian dapat diselesaikan setelah mengikuti kegiatan pengabdian PKM ini.
\end{abstract}

Kata kunci: keripik pisang, antioksidan, manajemen, marketing

\section{ABSTRACT}

Banana chips are generally still produced by home industries on a small scale. The home industry is constrained to increase production due to the lack of science and technology applications in the processing process and less of marketing techniques. Based on this problem we carried out the Program Kemitraan Masyarkat (PKM) with the partners of banana chips producers in the Bukit Rayat, Pekanbaru City, Riau Province. The service activities carried out were training in making banana chips containing antioxidants, equipment and material assistance to increase production, entrepreneurship management training, technical guidance on marketing and cooperation strategies, help in packaging label design, help to get P-IRT license and halal certificate. The results of this PKM are increasing patners skills in producing banana chips, increasing production scale, banana chips products with P-IRT license and halal certificates, enhancement of partner income. From this PKM it can be concluded that the problems of partners before this PKM can be resolved after participating in the PKM activities.

Key words: banana chips, antioxidants, entrepreneurship, management 


\section{PENDAHULUAN}

Buah pisang merupakan salah satu buah yang banyak memiliki manfaat. Buah pisang memiliki kandungan gizi yang baik, merupakan sumber energi yang cukup tinggi dibandingkan dengan buah-buahan yang lain. Pisang menghasilkan energi 136 kalori per $100 \mathrm{~g}$. Buah pisang kaya akan mineral seperti kalium, magnesium, besi, fosfor, dan kalsium, mengandung vitamin $\mathrm{B}$ dan $\mathrm{C}$, provitamin $\mathrm{A}$ (betakaroten). Buah pisang dapat dikonsumsi dalam bentuk segar ataupun diolah menjadi bentuk makanan lain seperti pisang rebus, goreng pisang, kolak pisang, keripik pisang, dan aneka bentuk olahan makanan lainnya (Suyanti dan Supriyadi, 1998).

Salah satu bentuk olahan buah pisang yang banyak digemari masyarakat adalah keripik pisang. Pisang yang paling cocok untuk dibuat keripik adalah pisang batu atau pisang kepok. Jenis pisang ini memiliki bentuk yang bulat besar, daging buahnya padat, dan renyah setelah digoreng. Keripik pisang merupakan produk makanan ringan yang dibuat dari irisan buah pisang dan digoreng, dengan atau tanpa bahan tambahan makanan yang diizinkan (BSN, 1996).

Usaha keripik pisang merupakan salah satu usaha yang cukup menjanjikan secara ekonomi karena keripik pisang memiliki peminat yang cukup banyak. Mulai dari anakanak, remaja, orang tua menyukai keripik pisang. Untuk meningkatkan mutu dan penjualan keripik pisang, diperlukan sentuhan ilmu pengetahuan dan teknologi dalam pengolahan dan pengemasannya agar mutu dan penjualan keripik pisang meningkat. Kualitas produk berpengaruh signifikan terhadap keputusan konsumen dalam membeli produk keripik pisang. Ada empat hal yang mempengaruhi pemasaran keripik pisang yaitu produk, tempat, promosi, dan harga (Budiwati, 2012)

Permasalahan yang dihadapi oleh mitra pengabdian ini diantaranya keripik pisang masih diproduksi dengan skala kecil karena modal untuk membeli peralatan kurang Pengetahuan mitra masih kurang tentang pemilihan bahan baku yang tepat dan pemanfaatan kunyit yang berfungsi sebagai antioksidan, pewarna, pengawet, dan pemberi aroma alami. Keripik pisang yang dihasilkan hanya satu rasa yaitu asin, kemasan yang digunakan masih sederhana dan belum ada label kemasan, belum memiliki izin edar dari dinas kesehatan kota dan belum memiliki sertifikasi halal dari LPOM MUI. Mitra belum optimal dalam manajemen sumber daya dan strategi marketing.

\section{TINJAUAN PUSTAKA}

Kunyit mengandung senyawa kurkumin dan minyak atsiri yang telah diteliti memiliki banyak khasiat dalam pengobatan. Kunyit digunakan dalam industri makanan, minuman, kosmetik, dan industri farmasi sebagai bahan tambahan alami sebagai pemberi warna, rasa, dan aroma. Industri makanan dan industri lainnya saat ini lebih fokus pada penggunaan bahan tambahan alami dibandingkan bahan tambahan kimia sintesis karena bahayanya bagi kesehatan. Oleh karena itu kunyit menjadi salah satu alternatif bahan tambahan alami, karena mudah diekstraksi menggunakan minyak (Das, 2016). Penambahan kunyit 5\% pada yuka (snack nasi goreng) terbukti menurunkan aktivitas radikal bebas (Lim and Han, 2016). Penambahan kunyit pada proses pengolahan keripik pisang dapat berfungsi sebagai antioksidan, pewarna, pengawet, dan pemberi aroma.

Untuk menggoreng keripik pisang dibutuhkan minyak dalam jumlah yang banyak dan digunakan berulang. Pemakaian minyak goreng secara berulang dengan suhu yang tinggi akan meningkatkan bilangan peroksida dan asam lemak bebas pada 
minyak. Hal ini mengurangi mutu minyak goreng dan hasil penggorengannya (Kartini et al., 2016). Untuk mengatasi hal ini diperlukan senyawa antioksidan. Salah satu antioksidan alami yang dapat digunakan untuk mencegah terjadinya oksidasi pada minyak goreng adalah kunyit. Pemanfaatan kunyit sebagai antioksidan alami dapat mempertahankan mutu minyak goreng karena mampu memperlambat kerusakan pada minyak akibat proses oksidasi. Kunyit dapat menurunkan bilangan peroksida dan asam lemak bebas pada minyak goreng (Nurminha, 2015; Perwitasari, 2009).

Usaha keripik pisang merupakan salah satu usaha yang cukup menjanjikan secara ekonomi karena keripik pisang memiliki peminat yang cukup banyak. Mulai dari anakanak, remaja, orang tua menyukai keripik pisang. Untuk meningkatkan mutu dan penjualan keripik pisang, diperlukan sentuhan ilmu pengetahuan dan teknologi dalam pengolahan dan pengemasannya agar mutu dan penjualan keripik pisang meningkat. Kualitas produk berpengaruh signifikan terhadap keputusan konsumen dalam membeli produk keripik pisang. Ada empat hal yang mempengaruhi pemasaran keripik pisang yaitu produk, tempat, promosi, dan harga (Budiwati, 2012).

Selain menghasilkan keripik pisang, proses pengolahan keripik pisang juga menghasilkan limbah kulit pisang. Kulit pisang selama ini hanya menjadi limbah yang belum dimanfaatkan. Kulit pisang mengandung serat yang tinggi. Limbah kulit pisang dapat diolah dan dimanfaatkan menjadi produk kerupuk kulit pisang (Herawati, 2017).

\section{METODE PELAKSANAAN}

\section{Tahap Persiapan}

Tahap persiapan merupakan tahap yang diperlukan untuk mengumpulkan informasi terakhir berkaitan dengan dasar-dasar pelaksanaan kegiatan dan mempersiapkan segala sesuatu yang diperlukan dalam pelaksanaan kegiatan.

Tahap persiapan ini terdiri dari :

1. Menghubungi mitra produsen keripik pisang dan berdiskusi tentang permasalahan yang dihadapi oleh mitra.

2. Diskusi dengan anggota pelaksana kegiatan dan penentuan pembagian beban kerja diantara anggota tim.

3. Mempersiapkan peralatan serta bahan yang diperlukan dalam pelaksanaan pelatihan.

4. Menjalin komunikasi dengan instansi-instansi lain yang terkait dalam pelaksanaan kegiatan.

\section{Tahap Pelaksanaan Kegiatan}

Tahap ini merupakan tahap yang pelaksanakan kegiatan. Tahap ini terdiri dari :

1. Tahap pertama

Pada tahap ini diberikan penyuluhan tentang pembekalan dasar-dasar teoritis yang berkaitan dengan ilmu pengetahuan dan teknologi yang meliputi :
a. Pemilihan bahan baku pisang kepok yang berkualitas
b. Penggunaan kunyit yang berfungsi sebagai antioksidan, pewarna, pengawet, dan pemberi aroma alami.
c. Pengetahuan mengenai sanitasi
d. Cara pengemasan produk

2. Tahap kedua 
Pada tahap ini merupakan tahapan melakukan praktek/pelatihan teknologi pembuatan keripik pisang dengan pemanfaatan kunyit dengan teknologi sederhana sesuai dengan teoritis yang telah diberikan sebelumnya.

3. Tahap ketiga

Pada tahap ini dilakukan pemberian bantuan peralatan yang mendukung produksi.

4. Tahap keempat

Pada tahap ini dilakukan pelatihan pelatihan manajemen sumber daya, strategi pemasaran, kiat-kiat menuju usaha mandiri berkelanjutan, membantu mitra untuk menjalin kerjasama dengan mitra pemasaran produk yang dihasilkan.

5. Tahap kelima

Pada tahap ini membantu kelompok usaha untuk menguruskan izin PIRT ke Dinas Kesehatan Kota Pekanbaru dan membantu mengurus sertifikat halal ke LPOM MUI Pekanbaru.

6. Tahap keenam

Tahap ini merupakan tahap monitoring dan pembinaan terhadap mitra produsen keripik pisang agar konsisten dalam mengembangkan usahanya. Data hasil monitoring dan evaluasi dibahas oleh tim pelaksana kegiatan, membantu mitra mencarikan solusi jika masih ada kendala yang dihadapi dan selanjutnya data hasil pembahasan tersebut diolah dan disusun menjadi suatu laporan.

\section{Evaluasi dan Kriteria Keberhasilan}

Kegiatan evaluasi program pengabdian ini dilakukan melalui pengamatan langsung terhadap keterampilan mitra setelah mengikuti kegiatan ini dengan menilai keterampilan mitra mulai dari persiapan (pemilihan bahan, penimbangan, penyiapan alat), penggunaan peralatan yang benar, ketepatan langkah-langkah mengolah produk, kesesuaian hasil akhir yang dipresentasikan menurut kreteria yang diharapkan dalam resep, menata peralatan setelah mengolah, teknik pengemasan, analisis untuk menghitung rugi /laba produk

\section{HASIL DAN PEMBAHASAN}

Hasil yang sudah dicapai dari kegiatan Program Kemitraan Masyarakat ini antara lain:

1. Mitra mengikuti kegiatan pelatihan pembuatan keripik pisang mengandung antioksidan. Mitra mendapatkan ilmu tentang cara pemilihan bahan baku keripik pisang yang berkualitas, proses pengolahan keripik pisang menggunakan kunyit sebagai sumber antioksidan sekaligus sebagai pewarna alami (Gambar 1).

2. Mitra mendapatkan bantuan alat dan bahan yang diperlukan untuk meningkatkan produksi keripik pisang.

3. Mitra mengikuti workshop manajemen SDM kewirausahaan sehingga mitra mampu mengelola SDM yang ada dan dapat membagi tugas secara efektif dan efisien (Gambar 2)

4. Mitra mengikuti bimbingan teknis strategi marketing dan kerjasama. Mitra dapat menyusun strategi marketing dan mampu menjalin kerjasama dengan swalayan atau toko makanan untuk menitipkan produk keripik pisang.

5. Mitra mengikuti kegiatan penyuluhan keamanan pangan yang dilaksanakan oleh Dinas Kesehatan Kota Pekanbaru. Melalui kegiatan ini mitra memahami tentang pentingnya kebersihan pada proses pengolahan makanan, memahami prosedur 
pengurusan izin P-IRT dan sertifikat halal. Sertifikat kegiatan ini merupakan salah satu syarat untuk pengurusan izin P-IRT (Gambar 3).

6. Produk keripik pisang mitra memiliki izin P-IRT dan sertifikat halal

7. Produk keripik pisang mitra sudah menggunakan kemasan STP Alufoil kombinasi plus zipper dan memiliki label kemasan sehingga tampilan produk lebih menarik dan konsumen mendapatkan informasi yang jelas tentang produk (Gambar4).

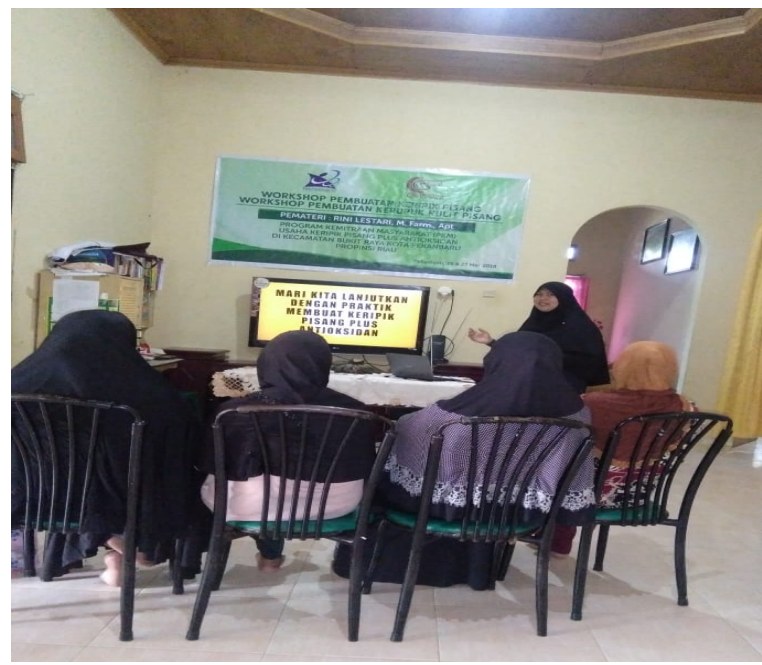

Gambar 1. Pemaparan materi pembuatan keripik pisang

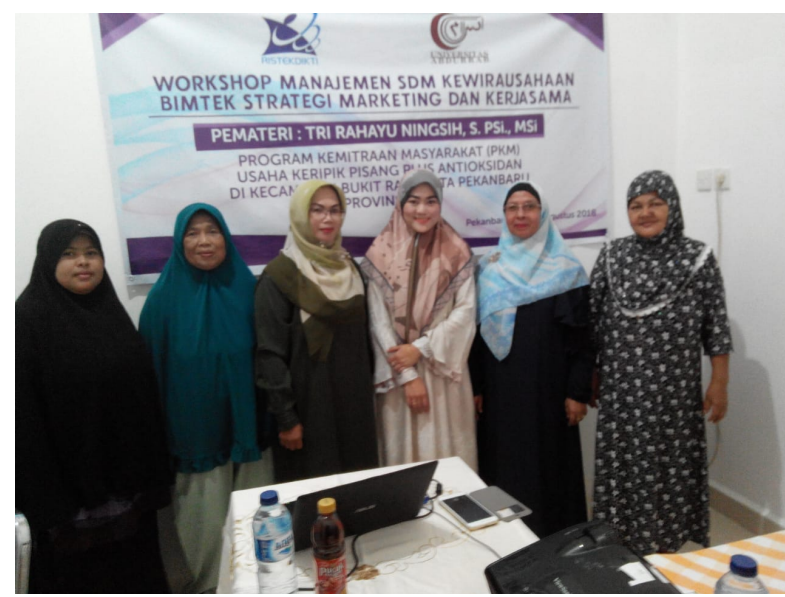

Gambar 2. Pelatihan manajemen SDM dan pemasaran 


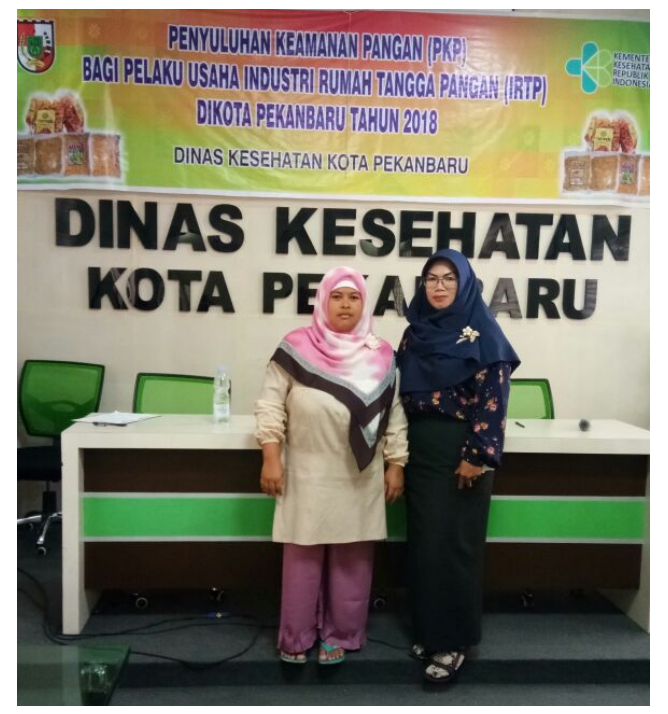

Gambar 3. Penyuluhan keamanan pangan

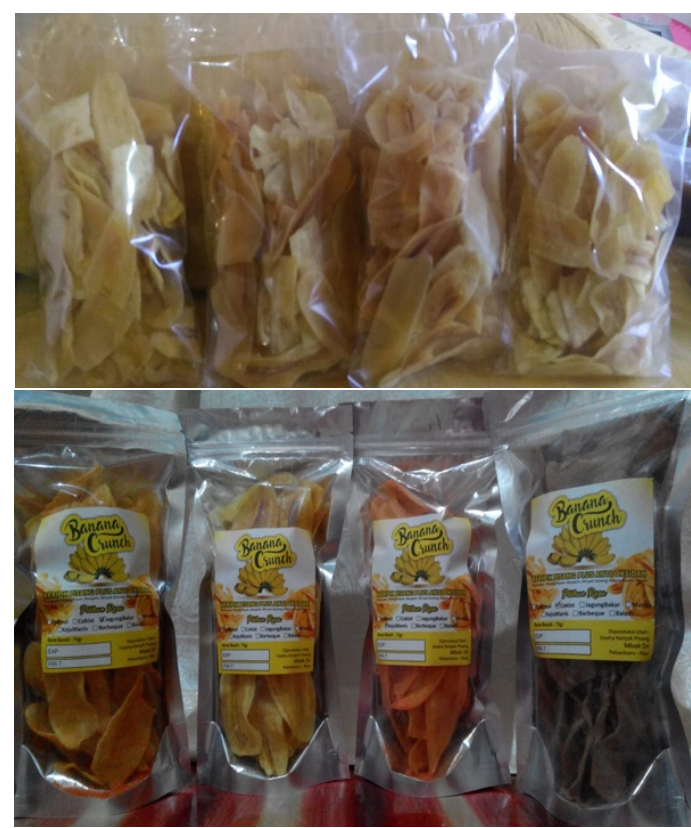

Gambar 4. Produk keripik pisang sebelum dan sesudah PKM

\section{KESIMPULAN}

Dari kegiatan pengabdian PKM yang sudah dilaksanakan dapat disimpulkan bahwa setelah mengikuti PKM ini keterampilan mitra dalam memproduksi keripik pisang meningkat, peningkatan skala produksi, produk keripik pisang memiliki izin P-IRT dan sertifikat halal, peningkatan penghasilan mitra menjadi dua kali lipat dari sebelumnya. Permasalahan yang dihadapi oleh mitra sebelum kegiatan pengabdian dapat diselesaikan setelah mengikuti kegiatan pengabdian PKM ini.

Untuk keberhasilan kegiatan ini perlu adanya monitoring, evaluasi, dan pendampingan berkelanjutan agar mitra tetap semangat dalam menjalankan usahanya dan usaha ini terus berkembang. Penulis mengucapkan terima kasih kepada semua 
pihak yang telah membantu dan memberikan dukungan atas terlaksananya kegiatan PKM ini.

\section{DAFTAR PUSTAKA}

Badan Standardisasi Nasional. 1996. Standar Nasional Indonesia Nomor 01-4315-1996 Tentang Keripik Pisang.

Budiwati, H. 2012. Implementasi Marketing Mix dan Pengaruhnya Terhadap Keputusan Pembelian Konsumen Pada Produk Unggulan Keripik Pisang Agung di Kabupaten Lumajang. Jurnal WIGA, Volume 2, Nomor 2, September 2012.

Das, K. 2016. Essential Oils in Food Preservation, Flavor and Safety. Chapter 5. Tumeric (Curcuma longa) Oils. P 835-841. Academic Press.

Herawati, H. 2017. Cara Membuat Keripik dan Kerupuk Kulit Pisang Mentah. http://carabuatresep.blogspot.co.id/2017/05/cara-membuat-keripik-kulit-pisangmentah.html. Diakses Juni 2017.

Kartini, S., Lestari, R., Putri, I. A., dan Rahmi, E. 2016. Hubungan Penggorengan Berulang dengan Angka Asam Minyak Bekas Penggorengan. Prosiding Seminar Hasil Penelitian Universitas Abdurrab. Desember 2016.

Lim, S.T. and Han, J. A. 2016. Improvement in Antioxidant Functionality and Shelf Life of Yukwa (Fried Rice Snack) by Turmeric (Curcuma longa L.) Powder Addition. Food Chemistry. Volume 199. P 590-596.

Nurminha. 2015. Pengaruh Penambahan Antioksidan Kunyit (Curcuma longa) Terhadap Bilangan peroksida Pada Minyak Goreng Curah. Jurnal analis Kesehatan, Volume 4, Nomor 1, Maret 2015.

Perwitasari, D. S. 2009. Penambahan Kunyit sebagai Antioksidan Alami pada Minyak Goreng Curah. Jurnal Teknologi Kimia, Volume 5, Nomor 1, Januari 2009.

Suyanti, dan Supriyadi, A., 2008. Pisang, Budi Daya, Pengolahan, dan Prospek Pasar. Jakarta : Penebar Swadaya 